\title{
Injury In Preschool-Age Children: A Population-Based Study
}

\author{
Achmad Surjono*, Soenarto Sastrowijoto**, \\ Siswanto Agus Wilopo"*** and Harun Rusito ${ }^{\star \star \star \star \star}$
}

(Community Health and Nutrition Research Laboratory Department of Child Health*, Ear-Nose \& Throats ${ }^{\star *}$, Public Health ${ }^{\star \star *}$, Medical School, Gajah Mada University, Yogyakarta; District Health Office ${ }^{\star * * *}$, Purwurejo, Indonesia)

ABSTRACT A study on the type and frequency of injuries in preschool-age children was conducted in a sample of households representing population of Purworejo district, A conducted in a sample of households representing popted select 4.354 preschool-age children living
two stages cluster (wilcah) method was used to seler
in 12,721 households in the district. The mother or other child caretakers provided responses about injuries occurring during the 3 months period to interview. Injuries among these preschool-age children included trauma by cutting or sharp object $(6.5 \%)$, falls $(5.7 \%)$, burns $(0.6 \%)$, bites $(0.4 \%)$, traffic accident $(0.4 \%)$, unconsciousness $(0.2 \%)$ and poisoning $(0.1 \%)$. The typical injury in under the 12 months aged 12 to 23 months accounted for $18 \%$ of the injury episodes $76.6 \%$ of injury episodes which were typically trauma, falls, burns, bites and terved between urban and rural arences in the frequency and type on injuries wed and type of injuries from this population-based study can be used in planning injury prevention especially for family health education program. [Paediatr Indones 1995; 35:231-235]

\section{Introduction}

Childhood injury is now being given appropriate attention due to childhood mortality and morbidity decrease by ad-

Accepted for publication: August 21, 1995. Author's address: Achmad Suryono, MD, Department of Child Health, Medical School, Gadjah Mada University, Jl. Kesehatan 1. Yogyakarta, Indonesia. vanced medicine in the health program. In some developed countries it becomes the main cause of death and disability in children. ${ }^{1,2}$ WHO together with other international, regional and national organizations develop activities toward a better control of childhood injury. ${ }^{3,4}$

This notable trend may not be well appreciated, especially in developing coun- 
tries, because of incomplete of faulty collection of data and unrecorded. The study of childhood injuries and accidents is hampered by imprecise definition and misclassification..$^{5-7}$ The terminology used is often subject to extensive discussions. Haddon $\& \mathrm{Baker}^{8}$ define an injury as an energy (e.g. chemical, mechanical, thermal, electrical, etc.) transfer from a haz ardous agent to a susceptible host in a conducive environment (physical and social) such that the host sustains physica damage.

The Indonesian National Household Surveys (1980, 1986, 1992) ${ }^{9}$ showed a decrease of most infectious diseases and prevalence of malnutrition. Consequently communicable diseases as major causes of mortality and morbidity will be replaced by non-communicable diseases. Some diseases or disorders are expected to increase during next 25 years including accidents, injuries, poisoning and pollution.

The present study describes the proportion and type of injuries in under-5 years old children in the community and compares the injury characteristics between urban and rural areas.

\section{Methods}

Data collection on injury in children was conducted in the Community Health and Nutritional Laboratory, Purworejo district, Central Java. The sample of the surveillance system was calculated approximately 13,000 households to cover the most of specific objectives, representative for the district's total population of 729,825 . A two stages cluster (wilcah) sampling method with Probability Proportional to Estimated Size (PPES) was used. Standardized questionnaires were used by trained, high school educated interviers to collect the injuries occurring during the 3 months prior to interview. Injuries were grouped into 7 categories in accordance with the National Household Survey criteria. Place where to seek help concerning injuries were recorded besides age, sex and origin. The quality of data collection was monitored by field supervisors and completed a series of data checks in the field.

Data entry was equipped with error screening for data type, range and logical checks. Data analysis was performed with Epi Info version 6 computer program for frequency distribution and chi-square calculations.

\section{Results}

An amount of 4.345 preschool children living in 12,721 households was included in the study. Five hundred thirty four children lived in urban environment.

Table 1 showed that the majority of injuries were trauma by cutting or sharp object and falls. The frequency of injury episodes in the under 1 year, 1 year, and more than 1 year age group were $5.4 \%$

$18 \%$ and $76.6 \%$ respectively. The typical injuries in the under 12 months olds were falls, that of in the age group of 12-23 months were falls and trauma while in the older group varied (Table 2).

There were 60 injury episodes out of 534 children in the under urban compared to 518 cases among 3,920 children in the rural area. No statistical differences
Table 1. Injury in children aged $0-4$ years during a 3 month period $(n=4354)$

\begin{tabular}{lcc}
\hline $\begin{array}{l}\text { Trauma by cutting, } \\
\text { sharp objects }\end{array}$ & 258 & $6.5 \%$ \\
Falls & 223 & $5.7 \%$ \\
Burns & 27 & $0.6 \%$ \\
Bites & 15 & $0.4 \%$ \\
Traffic accidents & 14 & $0.4 \%$ \\
Shock/unconscious & 8 & $0.2 \%$ \\
Poisoning & 6 & $0.1 \%$
\end{tabular}

\section{Table 2. Type of injury by age group}

\begin{tabular}{lccccc}
\hline $\begin{array}{l}\text { Age distribution } \\
\text { (years) }\end{array}$ & 0 & $12-4$ & \multicolumn{2}{c}{ Total } \\
\hline $\begin{array}{l}\text { Trauma by cutting } \\
\text { or sharp objects }\end{array}$ & 1 & 28 & 256 & 285 \\
$\begin{array}{l}\text { Falls } \\
\text { Burns }\end{array}$ & 29 & 68 & 130 & 223 \\
Bites & - & & 1 & 14 & 15 \\
$\begin{array}{l}\text { Traffic accidents } \\
\text { Shock/unconscious }\end{array}$ & 1 & 3 & 4 & 8 \\
$\begin{array}{l}\text { ness } \\
\text { Poisoning }\end{array}$ & - & - & 14 & 14 \\
\end{tabular}

on its frequency and the type of injury were observed.
Sixty percent of injuries were self medicated and $15 \%$ seeked help to health center 6 doctor private practice, $5 \%$ nurse private practice, $2 \%$ bone healer, $1 \%$ hospital and others.

\section{Discussion}

In this study the events were based on recall over a 3 -month period. Information ascertained retrospectively through mothers reports may be subject to bias due to differential recall pattern. ${ }^{10.11}$ There are two main reason for recall bias: 1 ) memory decay-the loss of information due to failure to recall the event, and 2) the telescoping effect-the tendency to remember events in the past as if they occurred closer to the present than they really did. Harel et al. ${ }^{12}$ showed significantly declining rates for a 1 -month to a 12 -month recall period. The largest declines were found for the 0-trough 4-year-old age group and for minor injuries. Recall periods of between 1 and 3 months are recommended for use in population-based surveys.

The high frequency of injury due to fall $5.7 \%$ in this district should be considered. Sixty four percent of the deaf children visiting the Ear, Nose and Throat Department of the Dr. Sardjito Hospital had reported history of falls from bed during their sleep. ${ }^{13}$ This may suggest the importance of preventive measures against falls.

Morbidity from falls is large and results in the most frequent cause to bring the children to the emergency room and lead children to the emergency rootes ${ }^{14}$ Injuries from stairs and steps predominate, while 
beds, tables, and chairs are also common injury vehicles in children aged 0 to 4 years. For older ages in this group falls from bicycles and heights are added.

Grigorovic $^{15}$ reported the commonest risk situations involved falling from settees $(45 \%)$, cots $(12 \%)$, Prams $(12 \%)$ and tables $(4 \%)$. Burns and scalds occurred in $20 \%$ of the children with injury and wounds in $15 \%$, namely wounded by falling objects such as broken-glass, knives blades, or pens.

In this study on difference in the frequency and type on injuries was found between urban and rural settings. Thus one may conclude in the under years olds were mostly influenced by home environment and road and traffic condition were comparable.

Injuries to the under- 5 years children were fairly slight, no impact of injury was reported in this study. This impact could be measured by time in beds, hospitalization, limitations of activity or disability. Approximately $30 \%$ of injuries required care-seeking either to government or private health services in this district.

A developmental context to child behavior at different ages is helpful for preventive counseling. ${ }^{16}$ Topics on specific cognitive and physical limitations at a certain age should be communicated to presents in situations or activities that have a likelihood of injuries. The probability of the site of injury occurrence can be predicted.

Population based data on injuries can be used more clearly on opportunities for prevention. The prevention of injuries cannot be undertaken by health per- sonnel alone but should of multidisciplinary approach.

\section{References}

1. Pearn J. Childhood accidents as a global and regional problem. International Child Health 1991; 2:13-8.

2. Rivara FP, Thompson RS, Thompson DC. Calonge $\mathrm{N}$. Injuries to children and adolescents; impact on physical health. Pediatrics 1991; 88:783-8.

3. Santos-Ocampo PD. Childhood injury, a global problem. International Child Health 1992; 3:42-8.

4. WHO. Research on accident and injury prevention. Advisory Committee Report, ACHR 1988, Geneva.

5. Manciux M, Romer CJ. Accidents in childhood and adolescence, a priority problem worldwide. In: Accidents in WHO 1991; $1-6$ adolescence. Geneva:

6. Deane D. Child accident data; accessible and available? J Publ Hlth Med 1993; 15: 226-8,

7. Rivara FP, Calonge N, Thompson, RS Populations based study of uninten tional injury incidence and impact during childhood. Am J Publ Hlth 1989
$79: 990-4$.

8. Haddon WJ, Baker SP. Injury control. In: Clark D \& McMahon B, eds. Preventive and community medicine. Boston: Little Brown Co, 1986; 109-40.

9. Ministry of Health. National Household Survey 1980-1986-1992, Jakarta.

10. Tursz A. Collection of data on accidents in childhood; problems of method In: Manciaux M, Romer CJ, eds Accidents in childhood and adolescence Geneva: WHO 1991; 39-56.

11. Scheidt PC, Harel Y, Trumble AC et al The epidemiology of non fatal injuries among US children and youth. Am Publ Hlth, 1995; 85: 932-8.

12. Harel Y, Overpeck MD, Jones DH et al. The effect of recall on estimating annual nonfatal injury rates for children and adolescents. Am J Publ Hlth 1994; 84 . 599-605.
13. Soenarto S. The etiology of deafness in children at the Sardjito Hospital, Yogyakarta. Medical School Library, GMU, 1982.

14. Garretson LK, Gallagher SS. Falls in children and youth. Pediatr Clin North Am 1985; 32:153-62.
15. Grigorovic LP. Injuries to children can be avoided. Wld Hlth Forum 1988; 9:595-9.

16. Zuckerman BS, Duby J. Developmental approach to injury prevention. 